\title{
Market-share Changes and Net Flows of Equity Mutual Funds in the U.S.: Quantile Analysis
}

\author{
Miyoun Paek ${ }^{1}$ and Kwangsoo Ko ${ }^{2 * *}$ \\ ${ }^{I}$ Finance at Georgetown College and adjunct professor at the University of Cincinnati. \\ ${ }^{2}$ Department of Business Administration, College of Business, Pusan National University, 2, Busandaehak-ro 63beon-gil, \\ Geumjeong-gu, Busan 46241.
}

\begin{abstract}
This study compares market-share changes with net flows to revisit the fund flow-performance relationship in the sense of the heteroscedasticity of fund flows. Decomposing market-share change (net flow) into inflow and outflow shares and other parts (inflow and outflow) using equity fund data obtained from the EDGAR system and CRSP mutual fund data basis employed to explain fund investor behavior. Market-share changes have a convex relationship with past performance, but net flows do not. Quantile regressions show somewhat different behavior between market-share changes and net flows. A characteristic analysis shows that relatively large (small) funds in the high (low) performance domain play an important role in the convex relationship between market-share changes and past performance.
\end{abstract}

JEL Classification: G10, G11.

Keywords: Market-share changes, Net flows, Convexity, Agency problem, Quantile analysis.

\section{INTRODUCTION}

Mutual fund net flows are an indicator of a change in a fund family's profits as well as a result of fund investors' decision making. Previous studies interpret and understand the behavior of fund investors by analyzing the equity fund net flows. Needless to say, prior performance is the most important factor that determines equity fund net flows. ${ }^{1}$ Ippolito (1992), Chevalier and Ellison (1997), and Sirri and Tufano (1998) show a convex or asymmetric relationship between net flows and past performance. Lynch and Musto (2003) and Huang, Wei, and Yan (2007) present theoretical models to explain the convex flow-performance relationship. These studies indicate that the best-performing funds induce disproportionately high net flows and the worst-performing funds do not face a serious decrease in total net assets (TNAs). For this reason, fund managers are attempting to artificially enhance fund performance, thus creating an incentive for them to be related to an agency problem between them and fund investors.

*Address correspondence to this author at Professor of Finance, Department of Business Administration, College of Business, Pusan National University, 2, Busandaehak-ro 63beon-gil, Geumjeong-gu, Busan 46241,

Tel: 051-510-3730. Fax: 051-581-8180; E-mail: kks1201@ pnu.edu or iloveksri@hanmail.net

\footnotetext{
${ }^{1}$ Other determinants include expense ratio, advertising and marketing strategy, tax, and cash flow volatility. See Barber, Odean, and Zheng (2005), Jain and Wu (2000), Bergstresser and Poterba (2002), Rakowski (2010), Rakowski and Wang (2009). Lee, Paek, $\mathrm{Ha}$, and Ko (2015) show international evidence for this relationship in the context of structural vector auto-regressions.
}

Spiegel and Zhang (2013) argue that such a relationship is the result of heterogeneous linear response functions between hot and cold money funds combined with the pooled analysis. They propose a measure of market-share changes instead of net flows to study the flow-performance relationship and conclude that the widely-held belief in the convex relationship is attributable solely to misspecification of the empirical model. That is, a market-share change is robust to the misspecification of empirical models. However, their empirical findings are also difficult to compare with those from previous studies, such as Sirri and Tufano (1998) and Chevalier and Ellison (1997), because their test procedures differ from those of others. This study also raises another important issue, which is the absence of homoscedasticity of fund flows among performance groups. This absence may invalidate the statistical tests of conventional piecewise pooled regressions, thus leading to an incorrect flowperformance relationship.

To induce additional fund flows on the basis of this convex relationship, fund managers or families attempt to enhance the performance of equity funds. There exists significant evidence related to the artificial enhancement of fund performance, including mutual fund tournaments by increasing volatility, the star phenomenon, portfolio pumping, wealth transfers by allocating good IPO stocks to specific equity funds, and so forth. ${ }^{2}$ Unfair enhancement of fund perfor-

\footnotetext{
2 See Brown, Harlow, and Starks (1996), Kempf and Ruenzi (2008), Nanda, Wang, and Zheng (2004), Carhart, Kaniel, Musto, and Reed (2002), Hu, McLean, Pontiff, and Wang (2014), and Gaspar, Massa, and Matos (2006).
} 
mance may cause an agency problem between fund investors and managers (or families). Recently, Huang, Sialm, and Zhang (2011) empirically demonstrate the agency problem by showing that funds that increase risk have worse performance than funds that maintain their risk levels over time.

Although numerous studies investigate this agency problem using fund net flows, market-share changes are more related to a fund family's profits. ${ }^{3}$ Spiegel and Zhang (2013) is a good example of finance study that uses market-share changes. In contrast, net flows are more related to the speed of a fund's growth. By definition, net flows are more sensitive to past performance for small funds than for large funds, however, market share changes are more sensitive to past performance for large funds than for small funds. These two fund flow measures are very useful for an economic analysis but have different properties. Then, which flow measure is more related to the agency problem between fund investors and managers: net flow or market-share change? If there exists an agency problem, a convex flow-performance relationship must be observed for the measure of fund flows. This issue can be addressed empirically.

In contrast, neither net flows nor market-share changes per semay fully represent an internal investment process of fund investors because they both represent a final summary consequence of their buying and redemption behavior. If buying and redemption of equity funds are not harmonized with each other as responses to past performance, cash inflows and outflows should be analyzed separately. ${ }^{4}$ While net flow is simply calculated by subtracting outflow from inflow, market-share change is not easily decomposed into inflow and outflow shares. Until now, very few studies separately investigate the inflows and outflows of equity mutual funds.

This study fills the gap between the current empirical findings and the unresolved dissues regarding the flowperformance relationship from a different perspective. Generally, cash flows do not show homogeneous dispersion among performance groups. In the sense of this heteroscedasticity of fund flows, this study compares market-share changes with net flows to revisit the fund flow-performance relationship. To further identify fund investors' decision making, we decompose market-share changes into inflow and outflow shares and other parts. We believe that our approach can provide new perspectives on the relationship.

The major empirical findings are as follows. First, marketshare changes have a convex relationship with past perfor-

\footnotetext{
${ }^{3}$ Market share not only reflects business profitability but also is a key indicator of market competitiveness as most economics and marketing studies use it as an evaluation measure for the effectiveness of a business strategy.

${ }^{4}$ The harmonization between inflows and outflows indicates that inflows (outflows) must have a positive (negative) correlation with past performance. Consequently, inflows have a negative correlation with outflows. Unfortunately, inflows have a significantly positive correlation with outflows, which can be incurred by a market practice (e.g., simultaneous behavior of large outflows by investors and large inflows by a fund sponsor), disposition effect, and so forth. According to Shefrin and Statman (1985), the disposition effect is to sell winners too early and to keep losers too long.
}

mance, but net flows do not. Second, for the convex relationship of market-share changes, outflow shares play an important role in the low performance domain and inflow shares play an important role in the middle and high performance domains. Third, quantile regressions show that net flows have a convex (concave) relationship for higher (lower) quantile funds but market-share changes have a convex relationship for all quantile funds. Finally, a characteristic analysis of quantile groups shows that relatively large funds in the high performance domain and relatively small funds in the low performance domain play an important role in the convex relationship of market-share changes with past performance. If market-share changes have a convex relationship with past performance, an agency problem exists between fund investors and managers because management fees are directly related to market shares. Hence, we conclude that market-share change suggested by Spiegel and Zhang (2013) is a better measure for fund flows than net flows from the viewpoint of the agency problem.

This paper is structured as follows. Section 2 describes the data used in this study. Section 3 defines fund flows, shows their behavior for the 20 performance groups, and decomposes market-share changes into inflow and outflow shares and other parts. Section 4 presents empirical evidence on convexity and flow decomposition. Section 5 employs quantile regressions to correct the problems generated from the absence of homoscedasticity of fund flows among performance groups. A characteristic analysis of quantile funds shows why convexity is observed for market-share changes. The final section concludes the paper.

\section{DATA}

Equity fund data are obtained from the Center for Research in Security Prices (CRSP) mutual fund database and the Securities Exchange Commission's Electronic Data Gathering, Analysis, and Retrieval (SEC's EDGAR) system. Monthly returns and total net assets (TNAs) for individual funds are obtained from the CRSP database. We do not estimate net flows from monthly returns and TNAs of equity funds. Rather, we collect cash inflows and outflows from the Form NSAR filings in the SEC EDGAR system and calculate net flows by subtracting outflows from inflows. Since 1994, a regulation under the Investment Company Act of 1940 has required Registered Investment Companies to file semiannual reports (Form N-SAR A/B) with the SEC, allowing our sample period to run from January 1994 to June 2013. This study analyzes actively managed U.S. domestic equity mutual funds. Following Edelen, Evans, and Kadlec (2012), a fund is defined at the portfolio level to include all share classes. The CRSP database provides various fund data at the share-class level. To create TNAs and monthly returns for a fund at the portfolio level, we aggregate all share-class TNAs and compute the TNA-weighted average returns. The CRSP fund data are manually merged with the EDGAR data by matching fund names because CRSP fund codes are not directly related to the N-SAR fund codes of the central index key (CIK). 
This study uses domestic equity funds of the following three styles: growth, growth and income, and mid- and small-cap. ${ }^{5}$ When we exclude exchange-traded funds (ETFs) and index funds, we obtain a total of 6,521 domestic equity funds $(18,206$ class funds).We match these funds with those from the EDGAR database to obtain 4,911 funds. Finally, among the 4,911 funds, we select 4,484 funds that have more than 12observations. The sample funds include 1,891 growth funds, 1,381 growth and income funds, and 1,212 mid- and small-cap funds.

Table 1 shows the descriptive statistics of 4,484 equity funds. In the first step, monthly average statistics are calculated during the sample period from January 1994 to June 2013. We compute cross-sectional averages using these monthly average statistics. As of June 2013, age represents the number of months since fund inception. Expense ratio includes $12 \mathrm{~b}-1$ fees. Panel A presents the general characteristics of the sample funds. The panel indicates an average return of 0.0058 , an average fund size of $\$ 748$ million, an average age of 150 months, and an average expense ratio of $1.26 \%$. The average turnover ratio is $90.57 \%$, which is consistent with the general expectation in the United States. Panels B, C, and D show that growth funds have the highest turnover ratio, that growth and income funds have the largest size and oldest age, and that mid- and small-cap funds have the highest return and expense ratio.

\section{Table 1. Descriptive Statistics of Sample Funds.}

This table shows the descriptive statistics of 4,484 equity funds. The time-series average statistics are calculated during the sample period from January 1994 to June 2013. Finally, we report crosssectional averages across sample funds in this table.

\begin{tabular}{|c|c|c|c|c|c|}
\hline & $\begin{array}{c}\text { Average } \\
\text { Return }\end{array}$ & $\begin{array}{c}\text { Average } \\
\text { TNAs } \\
\text { (\$million) }\end{array}$ & $\begin{array}{c}\text { Ages as } \\
\text { of JUNE } \\
\mathbf{2 0 1 4} \\
\text { (Months) }\end{array}$ & $\begin{array}{c}\text { Expense } \\
\text { Ratio }\end{array}$ & $\begin{array}{c}\text { Average } \\
\text { Turnover } \\
\text { Ratio }\end{array}$ \\
\hline \multicolumn{7}{|c|}{ Panel A: All equity funds (4,484 funds) } \\
\hline Average & .0058 & 748 & 150 & .0126 & .9057 \\
\hline Median & .0069 & 125 & 115 & .0123 & .7113 \\
\hline $\begin{array}{c}\text { Standard } \\
\text { deviation }\end{array}$ & .0102 & 3,063 & 135 & .0081 & 2.1878 \\
\hline \multicolumn{7}{|c|}{ Panel B: Growth funds (1,891 funds) } & \\
\hline Average & .0050 & 767 & 142 & .0134 & 1.0760 \\
\hline Median & .0066 & 101 & 104 & .0129 & .8126 \\
\hline $\begin{array}{c}\text { Standard } \\
\text { deviation }\end{array}$ & .0110 & 3,392 & 131 & .0097 & 3.2420 \\
\hline
\end{tabular}

5 According to the Strategic Insights classification from January 1994 to June 1998, AGG and GRO are selected for growth funds; GRI and ING for growth and income funds; and GMC and SCG for mid- and small-cap funds. On the basis of the Lipper classification from July 1998 to December 2013, CA and G are selected for growth funds; GI for growth and income funds; and MC, SG, and MR for mid- and small-cap funds.

\begin{tabular}{|c|c|c|c|c|c|}
\hline \multicolumn{6}{|c|}{ Panel C: Growth and income funds (1,381 funds) } \\
\hline Average & .0056 & 971 & 159 & .0103 & .6272 \\
\hline Median & .0062 & 140 & 108 & .0101 & .5242 \\
\hline $\begin{array}{c}\text { Standard } \\
\text { deviation }\end{array}$ & .0097 & 3,665 & 162 & .0051 & .7849 \\
\hline \multicolumn{7}{|c|}{ Panel D: Mid- and small-cap funds (1,212 funds) } \\
\hline Average & .0072 & 461 & 151 & .0140 & .9573 \\
\hline Median & .0082 & 141 & 135 & .0138 & .8002 \\
\hline $\begin{array}{c}\text { Standard } \\
\text { deviation }\end{array}$ & .0093 & 1,156 & 105 & .0077 & .6904 \\
\hline
\end{tabular}

\section{DEFINITIONS OF FUND FLOWS AND THEIR BE-} HAVIOR

\subsection{Decomposing Net Flows}

Huang et al. (2011) estimate net flow using the CRSP data as follows:

$$
\text { Netflow } w_{i, t}^{c r s p} \equiv \frac{T N A_{i, t}-T N A_{i, t-1}\left(1+r_{i, t}\right)}{T N A_{i, t-1}\left(1+r_{i, t}\right)}
$$

where Netflow $w_{i, t}^{\text {crsp }}$ is the CRSP net flow of the ith fund in month $\mathrm{t}, T N A_{i, t}$ is the TNAs of the ith fund at the end of month $\mathrm{t}$, and $r_{i, t}$ is the return of the ith fund in month $\mathrm{t} .{ }^{6} \mathrm{Be}-$ cause we collect fund inflows and outflows directly from the EDGAR database, net flows are easily obtained by subtracting outflows from inflows. We define EDGAR inflow, outflow, and net flow as follows: ${ }^{7}$

Inflow: Inflow $w_{i, t}^{\text {edgar }} \equiv \frac{\operatorname{In}_{i, t}^{\text {edgar }}}{T N A_{i, t-1}\left(1+r_{i, t}\right)}$,

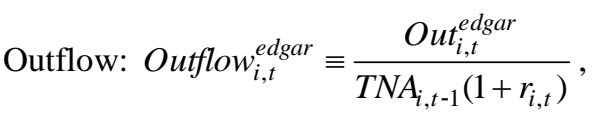

Net flow: Netflow $w_{i, t}^{\text {edgar }} \equiv \frac{\operatorname{Net}_{i, t}^{\text {edgar }}}{T N A_{i, t-1}\left(1+r_{i, t}\right)}$,

where $\operatorname{In}_{i, t}^{\text {edgar }}$ is the new sales of the ith fund in month $\mathrm{t}$, Out edgar is the redeemed cash of the ith fund in month t, $\operatorname{Net}_{i, t}^{\text {edgar }}\left(\equiv I n_{i, t}^{\text {edgar }}-\right.$ Out $\left._{i, t}^{\text {edgar }}\right)$ is net sales of the ith fund in month t,and $T N A_{i, t}$ isTNAs of the ith fund at the end of month t.

${ }^{6}$ Recently,Sialm, Starks, and Zhang (2015) use the same form of definition for defined contribution (DC) and non-DC flows.

${ }^{7}$ When we define EDGAR cash flows, we use TNA $\mathrm{A}_{\mathrm{i}-1}$ multiplied by the return of the $i^{\text {th }}$ fund in month $t$ as the denominator to be consistent with flow measure of Huang et al. (2011). 


\subsection{Decomposing Market-Share Changes}

Spiegel and Zhang (2013) propose market-share change (market-adjusted) as a new measure of fund flows. Marketshare change is defined as follows:

Market-share change:

$\Delta m_{i, t} \equiv m_{i, t}-m_{i, t-1}=\frac{T N A_{i, t}}{T N A_{t}^{*}}-\frac{T N A_{i, t-1}}{T N A_{t-1}}$,

where $\Delta m_{i, t}$ is the change in market share of the ith fund in month $\mathrm{t}, m_{i, t}$ is the market share of the ith fund at the end of month t, $T N A_{i, t}$ is the TNAs of the ith fund at the end of month $\mathrm{t}$, and $T N A_{t}$ is the total $T N A_{i, t}$ for all funds in month t. $T N A_{t}^{*}$ and $T N A_{t-1}$ are based on the funds that are in existence only in period $t-1$. The superscript $*$ indicates that it is the aggregate TNAs of the funds that were present at time t-
1. The measure of market-share changes cannot be easily decomposed, such as the aforementioned net flows in (2-3). We decompose market-share changes using the concepts of inflow and outflow shares as follows:

$$
\begin{aligned}
& \Delta m_{i, t} \equiv m_{i, t}-m_{i, t-1}=\frac{T N A_{i, t}}{T N A_{t}^{*}}-\frac{T N A_{i, t-1}}{T N A_{t-1}} \\
& =T N A_{i, t-1}\left[\frac{\left(1+r_{i, t}\right)}{T N A_{t}^{*}}-\frac{1}{T N A_{t-1}}\right]+\frac{N e t_{i, t}^{\text {crsp }}}{T N A_{t}^{*}} \\
& \left(\because N e t_{i, t}^{c r s p}=T N A_{i, t}-T N A_{i, t-1}\left(1+r_{i, t}\right) .\right) \\
& =T N A_{i, t-1}\left[\frac{\left(1+r_{i, t}\right)}{T N A_{t}^{*}}-\frac{1}{T N A_{t-1}}\right]+\left[\frac{N e t_{i, t}^{\text {edgar }}}{T N A_{t}^{*}}+\frac{\operatorname{Diff}_{i, t}}{T N A_{t}^{*}}\right]
\end{aligned}
$$

Table 2. Decomposition of Net Flows and Market-share Changes.

\begin{tabular}{|c|c|c|c|c|c|c|c|}
\hline \multicolumn{8}{|c|}{ Panel A. Cash flows of the CRSP and EDGAR } \\
\hline & \multicolumn{2}{|c|}{$\begin{array}{c}\text { CRSP } \\
\text { Net Flows }\end{array}$} & \multicolumn{2}{|c|}{ Net Flows } & Inflows & \multicolumn{2}{|c|}{ Outflows } \\
\hline Average & \multicolumn{2}{|c|}{$\begin{array}{c}.0042 \\
(13.28)^{* * * *_{a}}\end{array}$} & \multicolumn{2}{|c|}{$\begin{array}{c}.0039 \\
(12.96)^{* * *}\end{array}$} & $\begin{array}{c}.0285 \\
(85.01)^{* * *}\end{array}$ & \multicolumn{2}{|c|}{$\begin{array}{c}.0246 \\
(103.25)^{* * *}\end{array}$} \\
\hline Minimum value & \multicolumn{2}{|r|}{-.0957} & \multicolumn{2}{|c|}{-.1238} & .0000 & \multicolumn{2}{|c|}{.0000} \\
\hline First quartile & \multicolumn{2}{|r|}{-.0078} & \multicolumn{2}{|c|}{-.0078} & .0124 & \multicolumn{2}{|c|}{.0151} \\
\hline Median & \multicolumn{2}{|r|}{.0008} & \multicolumn{2}{|c|}{.0008} & .0236 & \multicolumn{2}{|c|}{.0223} \\
\hline Third quartile & \multicolumn{2}{|r|}{.0130} & \multicolumn{2}{|c|}{.0125} & .0385 & \multicolumn{2}{|c|}{.0310} \\
\hline & $\begin{array}{c}\text { Market-share } \\
\text { Changes }\end{array}$ & $\begin{array}{c}\text { Growth-from- } \\
\text { Return Shares (a) }\end{array}$ & $\begin{array}{l}\text { CRSP Net Flow } \\
\text { Shares (b) }\end{array}$ & $\begin{array}{c}\text { EDGAR Net } \\
\text { Flow Shares (c) }\end{array}$ & $\begin{array}{l}\text { Diff. btw. the Two } \\
\text { Net Flow Shares (d) }\end{array}$ & $\begin{array}{c}\text { Inflow Shares } \\
\text { (e) }\end{array}$ & $\begin{array}{c}\text { Outflow Shares } \\
\text { (f) }\end{array}$ \\
\hline \multirow{2}{*}{ Average } & -.0015 & -.0047 & .0032 & .0037 & -.0005 & .0665 & .0618 \\
\hline & $(-1.47)$ & $(-10.58)^{* * *}$ & $(3.88)^{* * *}$ & $(4.42)^{* * * *}$ & $(-3.53)^{* * *}$ & $(24.55)^{* * *}$ & $(24.16)^{* * *}$ \\
\hline Standard deviation & .0663 & .0298 & .0561 & .0557 & .0081 & .1786 & .1713 \\
\hline Minimum value & -1.2569 & -.7474 & -.7195 & -.7206 & -.1706 & .0000 & .0000 \\
\hline First quartile & -.0052 & -.0022 & -.0037 & -.0037 & -.0004 & .0025 & .0030 \\
\hline
\end{tabular}

This table shows the summary statistics for CRSP net flows, EDGAR cash flows, market-share changes, and each component of marketshare changes. Panel A compares EDGAR cash flows with CRSP net flows. Panel B presents each component of market-share changes. All figures in this table are computed after filtering out the top and bottom $0.5 \%$ tails of net flows and market-share changes.

a. *,**, and $* * *$ indicate statistical significance at the $10 \%, 5 \%$ and $1 \%$ levels, respectively. 


$$
\begin{aligned}
= & T N A_{i, t-1}\left[\frac{\left(1+r_{i, t}\right)}{T N A_{t}^{*}}-\frac{1}{T N A_{t-1}}\right]+ \\
& {\left[\frac{\text { In }_{i, t}^{\text {edgar }}}{T N A_{t}^{*}}-\frac{\text { Out }_{i, t}^{\text {edgar }}}{T N A_{t}^{*}}+\frac{D_{i f f}}{T N A_{t}^{*}}\right] }
\end{aligned}
$$

where Net $_{i, t}^{\text {edgar }}$ is the EDGAR net sales of the ith fund in month t, Net ${ }_{i, t}^{c r s p}$ is the CRSP net sales of the ith fund in month t, $\quad \operatorname{Diff}_{i, t}\left(=\right.$ Net $_{i, t}^{\text {crsp }}-$ Net $\left._{i, t}^{\text {edgar }}\right)$ is the difference between CRSP and EDGAR net sales, $I n_{i, t}^{\text {edgar }}$ is the new sales of the ith fund in month $\mathrm{t}$, and $O u t_{i, t}^{\text {edgar }}$ is the redeemed cash of the ith fund in month t. The non-negligible Diff $f_{i, t}$ is an inconsistency between CRSP and EDGAR databases. In equation (4), (a) is the characteristic of the ith fund related to its size and return, ${ }^{8}$ (b) is the net flow share estimated from the CRSP data, and (c) is the net-flow share computed from the EDGAR data; consequently, (d) is the difference in netflow shares between the CRSP and EDGAR data, (e) is the inflow share that represents the buying behavior of fund investors, and (f) is the outflow share that represents the redemption behavior of fund investors. For the decomposition to be appropriate, Diff $f_{i, t}$ should be negligible, which is easily shown by comparing or graphing CRSP and EDGAR netflow shares.

Our purpose for decomposing market-share change is to extract the net-flow share (c), the inflow share (e), and the outflow share (f) from market-share change. Our concern is whether or not the inflow, outflow, and net-flow shares will have the same pattern as observed in the inflows, outflows, and net flows in (2-1), (2-2), and (2-3), respectively. How do cash inflows or cash outflows drive the behavior of net flows and market-share changes? The analysis of our flow measures must provide clear answers to this question.

\subsection{Decomposition Results of Net Flows and Market- Share Changes}

Table 2 shows the summary statistics for CRSP net flows, EDGAR cash flows, and market-share changes. In our sample, outliers are filtered out as suggested by Huang et al. (2007) and Spiegel and Zhang (2013) to remove their effects on the flow-performance relationship. We conservatively filter out the top and bottom $0.5 \%$ tails of net flows and market-share changes. Panel A compares EDGAR cash flows with CRSP net flows. The CRSP and EDGAR net flows have very similar values, implying that the two databases are consistent with each other. Panel B presents each component of the market-share changes decomposed by equation (4). Because the CRSP and EDGAR databases provide very similar net flows in Panel A, the difference(d) between them must be negligible when compared with inflow and outflow

${ }^{8}$ If the $i^{\text {th }}$ fund's return in month $t$ is the same as that of the aggregate equity funds and inflows are the same as outflows in month t, the component (a) should be zero. shares. As expected, this difference is very small, albeit significantly negative, relative to the EDGAR net flow shares. This relationship allows us to use inflow share (e), outflow share (f), and net-flow share (c) to investigate the flowperformance relationship.

\subsection{Components of Cash Flows for the 20 Performance Groups}

As a preliminary approach to the flow-performance relationship, in Figure 1, we plot cash flows for the 20 performance groups as indicated by Sirri and Tufano (1998) and Spiegel and Zhang (2013).A fund is placed in a performance group on the basis of its past performance as measured by its styleadjusted return. A fund's style-adjusted return is defined as its return minus its style average return for that period. The lowest performing funds are placed in group 1 and the best are placed in group 20. For each group, the average of the cash flows in month $t$ is calculated and, finally, crosssectional averages are averaged again for all months. To allow for a variety of possibilities, we measure fund performance for various past periods: ${ }^{9}$ past 12 months, past 6 months, past 3 months, and past 1 month.

Panel A presents CRSP and EDGAR net flows for the 20 performance groups. The lines show a very similar pattern among all past periods, indicating that we need not be concerned about the past period to measure fund performance. Further, the two databases show almost the same figures, reconfirming the consistency between the CRSP and EDGAR databases. In the high performance groups, the patterns of the lines are similar to that in Sirri and Tufano (1998). The slope of the positive relationship is very steep for funds in the top 18th, 19th, and 20thvigintiles. A positive relationship is also observed in the lower performance groups, the 1st, 2nd, 3rd, 4th, and 5thvigintiles.A penalty seems to be incurred for extremely lower relative performance, which is different from the findings of previous studies such as Ippolito (1992), Chevalier and Ellison (1997), and Sirri and Tufano (1998). The different sample period from previous studies could be an important reason for such a different pattern. Figure 3 in Spiegel and Zhang (2013) shows a similar relationship pattern (net flows of market- and categoryadjusted returns) to that in this study. This finding is not supported by the prediction of Lynch and Musto (2003); however, their prediction does not necessarily apply to net flows because net flows are inflows (new money) minus outflows (old money).

Panel B presents the EDGAR inflows and outflows for the 20 performance groups. We also observe almost the same pattern for the past 12-month and 1-month performance measures. Surprisingly, inflows have an exactly convex relationship with performance, similar to the relationship observed in net flows by Sirri and Tufano (1998). A positive but relatively shallow relationship exists between performance and subsequent inflows. A marked bonus exists for extremely higher performing funds but no pronounced penalty for extremely lower performing funds. This shape of in-

${ }^{9}$ Sirri and Tufano (1998) and Spiegel and Zhang (2013) use past 12 month and 1-month returns as performance measures, respectively. 
flows (new money) seems to be supported by the prediction of Lynch and Musto (2003) that fund investors seek lower performing funds as prospective investments.

Outflows also have a convex relationship with performance but the shape is the reverse of that of inflows and the curvature is relatively flatter than for inflows. The outflows are relatively large for funds with extremely lower and higher performance. Observing large outflows seems natural for funds with extremely lower performance but not for funds with extremely higher performance. The disposition effect is likely to be closely related to the increase in outflows for funds with extremely higher performance. The combining behavior of inflows and outflows generates the net-flow behavior plotted in the solid line. The remarkable increase in outflows, i.e., the fast flight of old money, is a main cause of the penalty in net flows for extremely lower performing funds. This finding is inconsistent with the disposition effect in the loss domain. However, the outstanding increase in inflows, i.e., a flowing tide of new money, is the main cause of the marked bonus in net flows for extremely higher performing funds. Statistical tests will provide a clear conclusion for the flow-performance relationship.

Panel A. CRSP net flows and EDGAR net flows

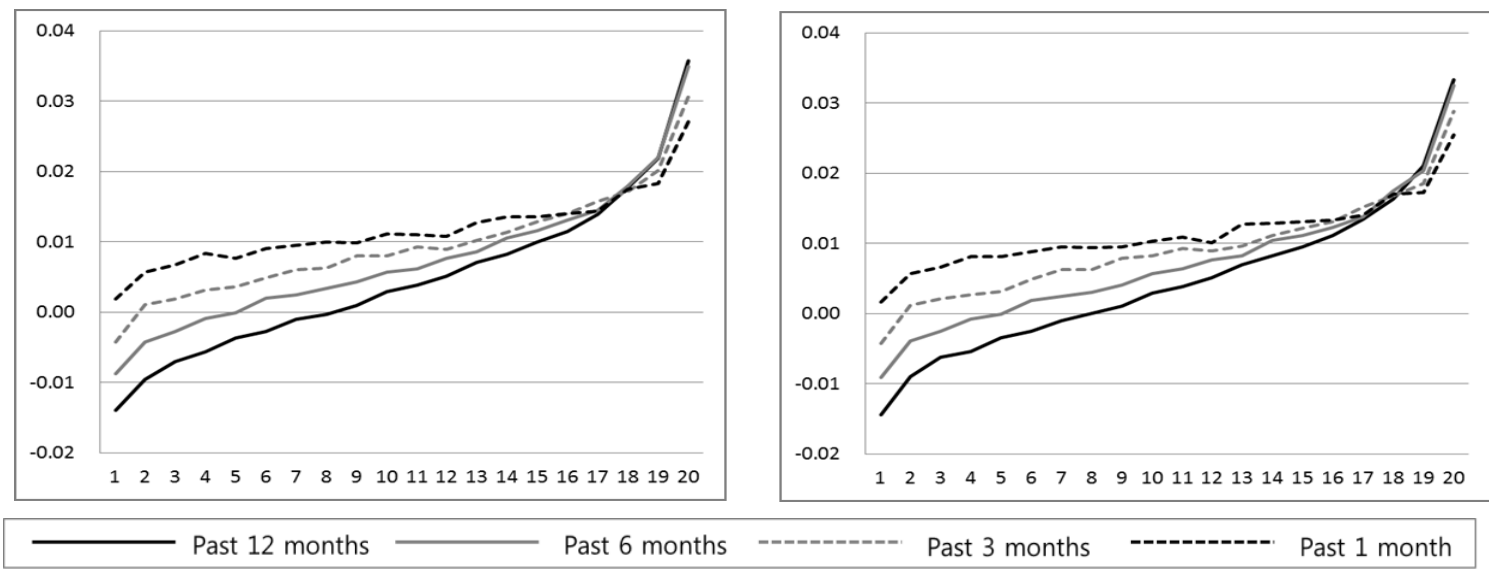

CRSP net flows EDGAR net flows

Panel B. EDGAR inflows and outflows
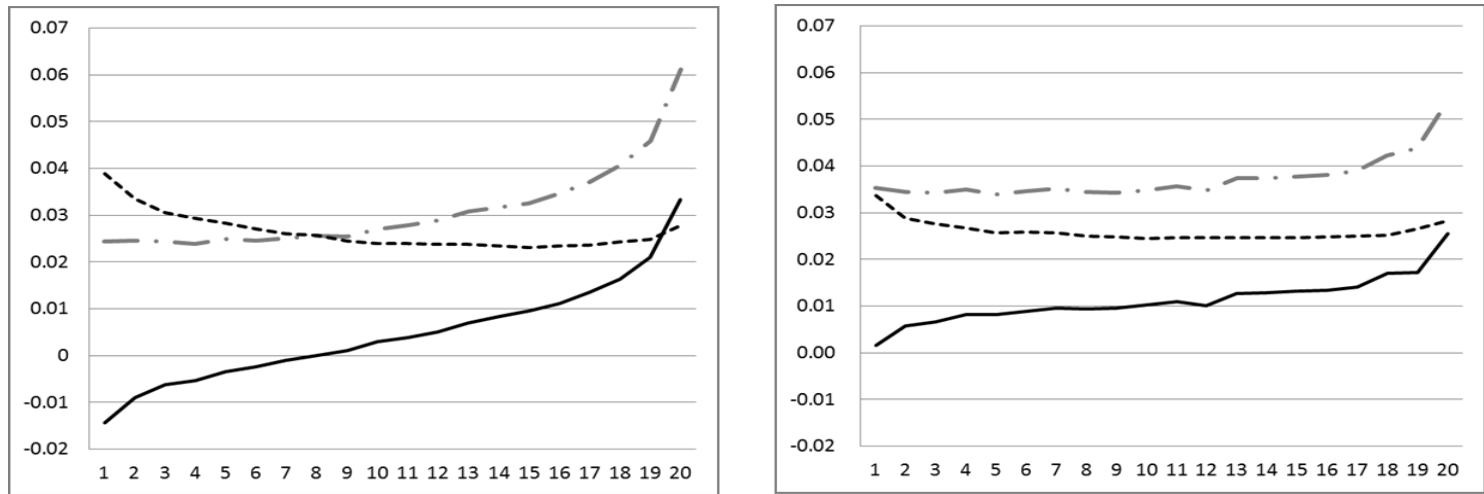

\begin{tabular}{|c|c|c|c|c|c|}
\hline$\longrightarrow$ & Net flows & $-\cdot-\cdot \cdot \cdot \cdot \cdot$ & Inflows & ----------- & Outflows \\
\hline
\end{tabular}

Past 12 months Past 1 month

Figure 1. Cash flows for the 20 performance groups. This figure shows the cash flows for the 20 performance groups. Panel A compares the graphs between CRSP net flows and EDGAR net flows for different periods to measure fund performance. Panel B compares EDGAR inflows and outflows using the past 12-month and past 1-month returns as a performance measure.

\subsection{Components of Market-Share Changes for the 20 Performance Groups}

As an alternative to net flows, we plot market-share changes for the 20 performance groups in Panel A of Fig. (2). When we use past 1-month return as a performance measure, the shape of the market-share changes becomes similar to that of net flows in Panel A of Fig. (1). However, when past 12month return is used as a performance measure, the shape of the market-share changes is similar to that of the net flows shown in Sirri and Tufano (1998). A marked bonus exists for significantly higher performance but no penalty is incurred for significantly lower performance. The only difference in the shape of the relationship from the net flows in Sirri and Tufano (1998) is that a positive relationship is more pronounced from the $5^{\text {th }}$ vigintile. The relationship between the past 12-month returns and the subsequent market-share changes is more similar to that in Sirri and Tufano (1998) 
Panel A. Market-share changes $\left(\times 10^{4}\right)$

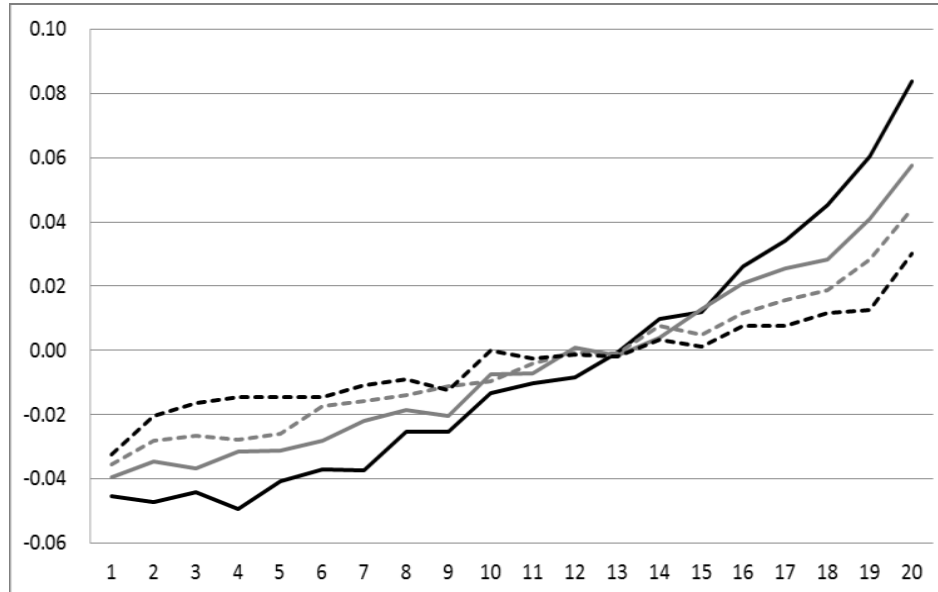

Past 12 months $\longrightarrow$ Past 6 months ----------- Past 3 months ----------- Past 1 month

Panel B. Decomposition of market-share changes $\left(\mathrm{x} 10^{4}\right)$
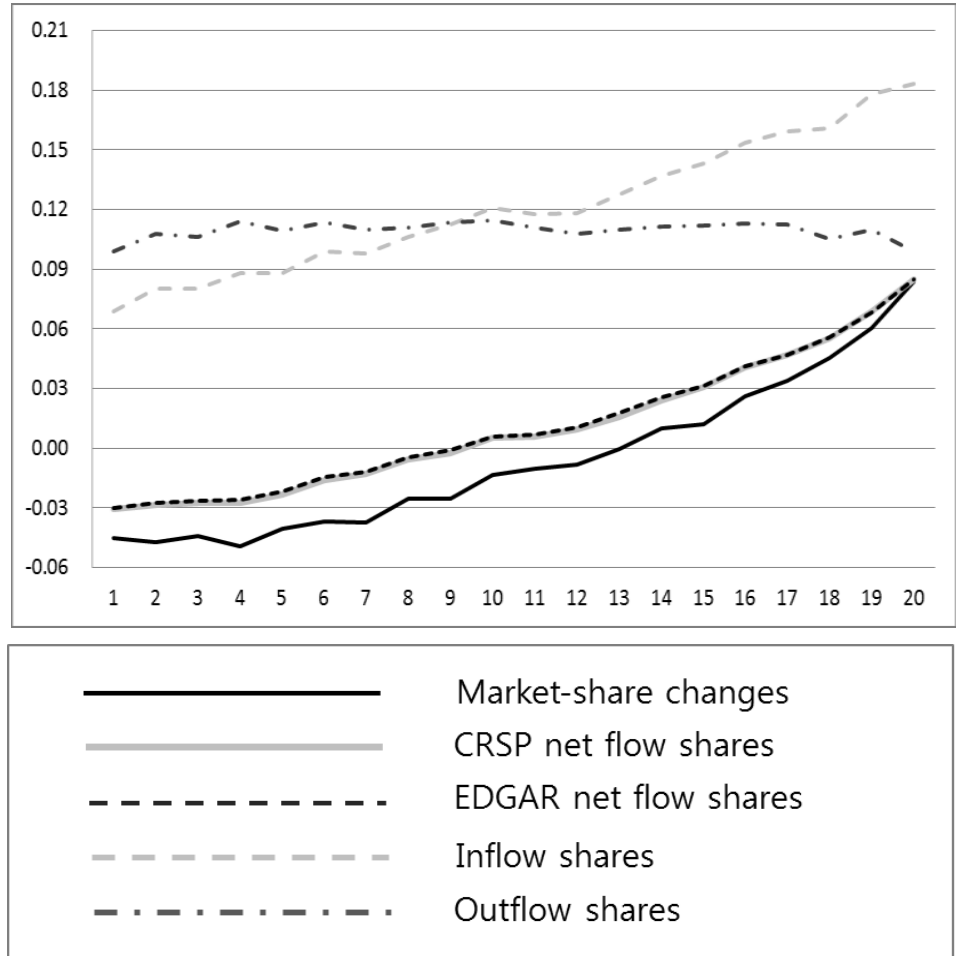

Fig. (2). Market-share changes for the 20 performance groups. This figure shows market-share changes, and inflow and outflow shares for the 20 performance groups. Panel A compares the graphs of market-share changes for different periods to measure fund performance. Panel B presents each component of market-share changes when the performance is measured for the past 12 months.

than the net flow-performance relationship presented in Panel A of Figure 1. The lines in Panel A of Fig. (2) show that the convexity strengthens as the past period for measuring fund performance becomes longer.

Panel B shows various components of market-share changes for the 20 performance groups when the performance is measured for the past 12 months. The CRSP and EDGAR net flow shares are plotted on the same line, which reconfirm that the two databases are consistent. Our concerns focus on inflow and outflow shares. At a first glance, inflow shares have a positive relationship with past performance but do not show a clear convex relationship. Outflow shares have an almost flat pattern over the performance groups with a small decrease in the left and right tails.

From Figs. (1 and 2), we understand that net flows and market-share changes have different relationships with past performance. Further, inflow and outflow shares for the 20 performance groups have different shapes from those of inflows and outflows, re65spectively. These findings indicate that both net flows and market-share changes are different from each other for understanding the behavior of fund investors. 


\section{EMPIRICAL EVIDENCE ON THE CONVEXITY AND FLOW DECOMPOSITION}

We define and decompose fund flows to explain the behavior of fund investors. This section attempts to test the convex flow-performance relationship using the following piecewise linear regression models. Following the previous studies (i.e., Chevalier and Ellison, 1997, and Sirri and Tufano, 1998), we rank funds based on their prior performance, ranking funds from zero for the worst performing fund to one for the best performing fund and spread each fund's performance ranking across tercile, low performance, mid performance, and high performance, and estimate a piecewise linear regression as following.

$$
\begin{aligned}
& \text { flow }_{i, t}=\alpha+\beta_{1} \text { Low }_{i, t-k: t-1}+\beta_{2} \text { Mid }_{i, t-k: t-1} \\
& +\beta_{3} \text { High }_{i, t-k: t-1}+e_{i, t} \\
& \text { flow }_{i, t}=\alpha+\beta_{1} \text { Low }_{i, t-k: t-1}+\beta_{2} \text { Mid }_{i, t-k: t-1}+\beta_{3} \text { High }_{i, t-k: t-1} \\
& +\gamma_{1} \text { SF }_{i, t}+\gamma_{2} \text { Fee }_{i, t}+\gamma_{3} \text { Age }_{i, t} \\
& +\gamma_{4} \text { Size }_{i, t}+\gamma_{5} \text { Vol }_{i, t}+\gamma_{6} \text { Turnover }_{i, t}+\gamma_{7} \text { FamilySize }_{i, t} \\
& +\gamma_{8} \text { Lagcf }_{i, t}+e_{i, t} \\
& \text { flow }_{i, t}=\alpha+\beta_{1} \text { Low }_{i, t-k: t-1}+\beta_{2} \text { Mid }_{i, t-k: t-1}+\beta_{3} \text { High }_{i, t-k: t-1} \\
& +\gamma_{1} \text { SF }_{i, t}+\gamma_{2} \text { Fee }_{i, t} \\
& +\gamma_{3} \text { Age }_{i, t}+\gamma_{4} \text { Size }_{i, t}+\gamma_{5} \text { Vol }_{i, t}+\gamma_{6} \text { Turnover }_{i, t}+\gamma_{7} \text { FamilySize }_{i, t} \\
& +\gamma_{8} \text { Lagcf }_{i, t}+\text { InstDummies }+ \text { StyleDDmmies } \\
& + \text { YearDummies }+e_{i, t}
\end{aligned}
$$

where flowi,t is a fund flow for the ith fund in month $\mathrm{t}, \operatorname{Low}_{i, t-k: t-1}=\min \left(\operatorname{Rank}_{i, t-k: t-1}, 0.2\right)$,

$\operatorname{Mid}_{i, t-k: t-1}=\min \left(\operatorname{Rank}_{i, t-k: t-1}-\operatorname{Low}_{i, t-k: t-1}, 0.6\right)$,

High $_{i, t-k: t-1}=$ Rank $_{i, t-k: t-1}-\operatorname{Low}_{i, t-k: t-1}-$ Mid $_{i, t-k: t-1}$,

Rank $_{i, t-k: t-1}$ is the performance rank of the ith fund from month t-k through montht-1 (normalized rank between 0 and 1). In this study, we consider that $\mathrm{k}$ is equal to 12 (i.e., prior 12 months for measuring fund performance) according to previous studies and the fund industry's evaluation practices. $S F_{i, t}$ is the cash flow in month $\mathrm{t}$ divided by the one-month lagged TNAs for all funds in the style category, $\mathrm{Fee}_{i, t}$ is the ith fund's annual expense ratio plus the actual $12 \mathrm{~b}-1$ fees in the prior calendar year, $A g e_{i, t}$ is the log of the ith fund's age in months since inception, Size $e_{i, t}$ is the log of the TNAs of the ith fund at the end of month $\mathrm{t}, \mathrm{Vol}_{i, t}$ is the standard deviation of the ith fund's return during the prior calendar year, ${ }^{10}$ Turnover $r_{i, t}$ is the CRSP turnover ratio of the ith fund during the prior calendar year, FamilySize $e_{i, t}$ is the log of the size of the ith fund's family at the end of month t, $\operatorname{Lagcf}_{i, t}$ is the value of the dependent variable of the ith fund in the prior month, InstDummies are dummy variables for institutional or retail funds, StyleDummies are dummy variables for fund style, and YearDummies are dummy variables for year. Equation (5) regresses the flow variable on piecewise performances without considering any control variables. Equation (6) controls for each fund's characteristics, and equation (7) further controls for various dummy variables as suggested by previous studies.

Table 3 shows the estimation results of the piecewise linear regressions for the flow-performance relationship. If the flow-performance relationship is convex, the coefficient of the higher performance domain should be larger than that of the lower performance domain in a statistical sense. That is, if High-Mid, Mid-Low, and High-Low have significantly positive coefficients, the flow-performance relationship is called convex. If they all have significantly negative coefficients, the relationship is called concave. High-Mid (MidLow) indicates the convexity or concavity in the middle and high (the low and middle) performance domains.

Panel A presents the results for EDGAR net flows, inflows, and outflows. In the case of net flows, the estimation results are very similar for all models except for the adjusted R2. The coefficient of High is largest among the explanatory variables (i.e., Low, Mid, and High), which is consistent with previous empirical studies. Such an investor response implies that the best-performing funds induce disproportionately high net flows. Such an inducement may trigger fund managers' excessive competition to artificially enhance fund performance, which may be related to an agency problem between fund investors and managers. However, contrary to previous studies such as Ippolito (1992), Sirri and Tufano (1998), and Chevalier and Ellison (1997), the coefficient of Low is the second largest among the explanatory variables. Consequently, the differences in the Mid and Low coefficients are all negative for equations (5), (6), and (7) in the lower part of Table 3, revealing even concavity in the low and middle performance domains. These negative differences confirm the non-existence of convexity in the net flowperformance relationship shown in Panel A of Figure 1, which contradicts the statement that the worst-performing funds do not face a serious decrease in TNAs. This finding could represent evidence of the absence of an agency problem in the low performance domain. Hence, we are unable to find any conventional convexity in the net flow-performance relationship during the sample period from January 1994 through June 2013.

However, in the case of inflows, the coefficient of High is largest and that of Low is smallest among the explanatory variables for all equations. Noteworthy is that the coefficient of Low is significantly negative. Lynch and Musto (2003) predict that strategy changes occur after bad performance and bad performers who change their strategy have dollar flows. Our finding on inflows, not net flows, in the low performance domain is completely consistent with the prediction model by Lynch and Musto (2003). In the lower part, the differences in coefficients confirm aconvexity in the

${ }^{10}$ The fund family in this study is a group of mutual funds managed by a single investment company in the U.S. 
Table 3. Piecewise Linear Regressions of EDGAR Cash Flows and Market-share Changes.

This table shows the estimation results of piecewise linear regressions for the flow-performance relationship. The first model in equation (5) does not include any control variables. The second model in equation (6) controls for each fund's characteristics. The third model in equation (7) further controls for various dummy variables. High-Mid, Mid-low, and High-low must have significantly positive coefficients for the flow-performance relationship to be convex. If they all have significantly negative coefficients, the relationship is concave. Panel A presents the estimation results for EDGAR net flows, inflows, and outflows. Panel B presents the estimation results for market-share changes, and inflow and outflow shares.

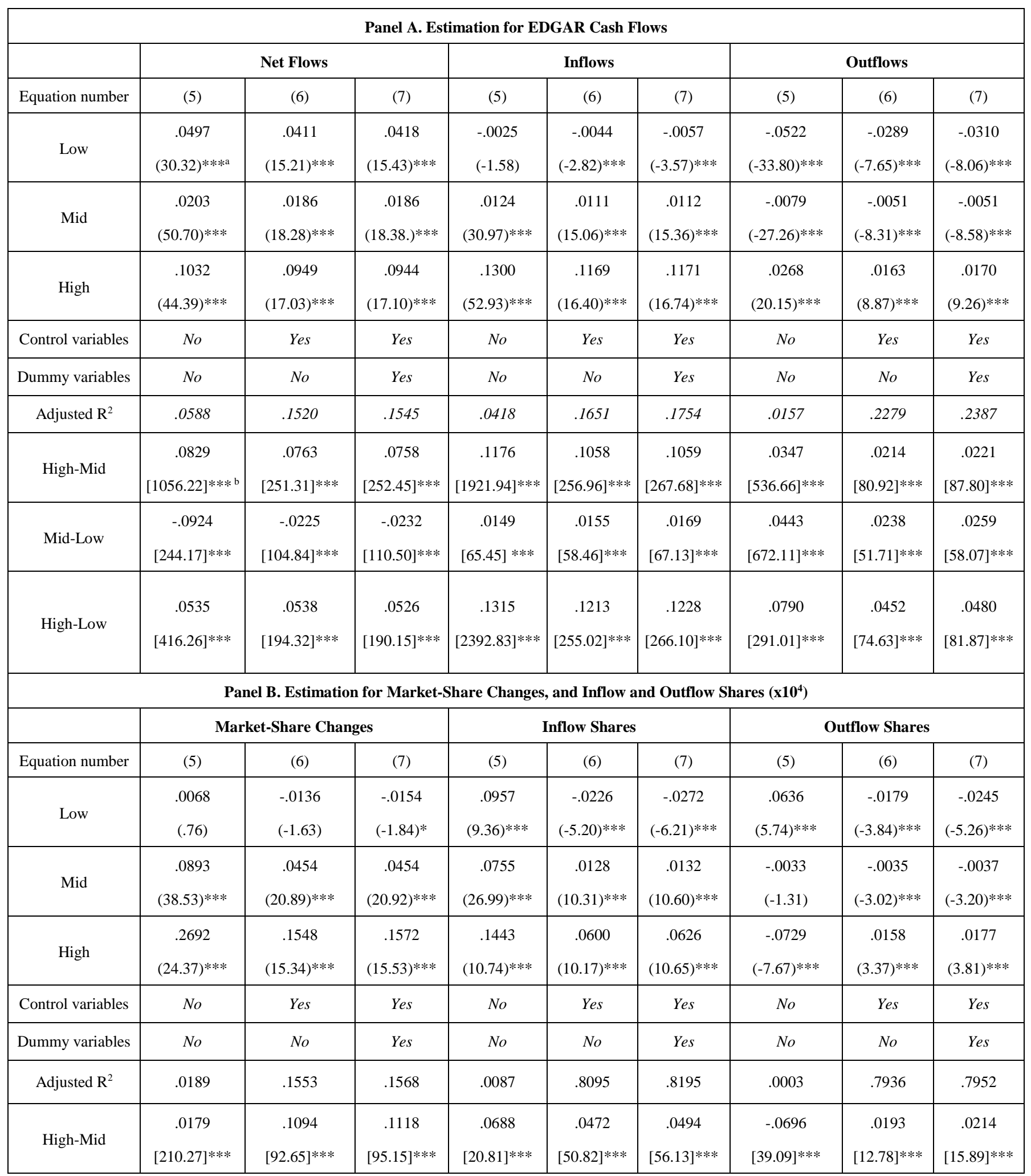




\begin{tabular}{|c|c|c|c|c|c|c|c|c|c|}
\hline Mid-Low & $\begin{array}{c}.0825 \\
{[63.08]^{* * *}}\end{array}$ & $\begin{array}{c}.0590 \\
{[37.02]^{* * *}}\end{array}$ & $\begin{array}{c}.0608 \\
{[39.42]^{* * *}}\end{array}$ & $\begin{array}{c}-.0202 \\
{[2.87]}\end{array}$ & $\begin{array}{c}.0354 \\
{[47.06]^{* * *}}\end{array}$ & $\begin{array}{c}0.0404 \\
{[60.57]^{* * *}}\end{array}$ & $\begin{array}{c}-.0669 \\
{[28.11]^{* * *}}\end{array}$ & $\begin{array}{c}.0144 \\
{[7.20]^{* * *}}\end{array}$ & $\begin{array}{c}.0208 \\
{[15.13]^{* * *}}\end{array}$ \\
\hline High-Low & .2624 & .1684 & .1726 & .0486 & .0826 & .0898 & -.1365 & .0337 & .0422 \\
{$[408.48]^{* * *}$} & {$[194.62]^{* * *}$} & {$[202.54]^{* * *}$} & {$[9.87]^{* * *}$} & {$[148.54]^{* * *}$} & {$[173.73]^{* * *}$} & {$[105.33]^{* * *}$} & {$[31.05]^{* * *}$} & {$[48.75]^{* * *}$} \\
\hline
\end{tabular}

a. t-statistics in parentheses are calculated using White heteroscedasticity-consistent standard errors. *, **, and *** indicate statistical significance at the $10 \%$, $5 \%$ and $1 \%$ levels, respectively.

b. $\chi^{2}$-statistics are in brackets. $*, * *$, and $* * *$ indicate statistical significance at the $10 \%, 5 \%$ and $1 \%$ levels, respectively.

inflow-performance relationship. Convexity is also found in the behavior of the outflows but its interpretation is somewhat different from that of the inflows. Outflows decrease with an increase in performance, but slightly increase in the high performance domain. This increase can be viewed as an asymmetric disposition effect that which is detectable only when we observe outflows behavior. ${ }^{11}$ The net flowperformance relationship is simply a consequence of the combination of the convex inflow- and outflow-performance relationships. However, the relationship between net flows and performance is not convex in this study because of a large volume of outflows in the low performance domain, and our finding contradicts the extant literature that analyzes the period before 1994 .

Panel B presents the results for market-share changes, and inflow and outflow shares. Unlike net flows, we find a convex relationship between market-share changes and past performance even though the coefficient of Low hasa negative sign for equations (6) and (7). The coefficient of High is largest and that of Low is smallest among the coefficients of performance variables. The differences in coefficients confirm the convex relationship. This finding is different from the non-convexity for market-share changes found by Spiegel and Zhang (2013). The difference could originate from the following two reasons. First, Spiegel and Zhang (2013) use past 1-month return as a performance measure while we use past 12-month return. Second, their piecewise break points vary with regression models while ours (i.e., $20 \%$ and $80 \%$ ) follow Sirri and Tufano (1998). We believe that their findings would be the same as ours if they follow our procedures. ${ }^{12}$ Interestingly, the convex relationship for net flows found before 1994 is now observed for market-share changes from January 1994 through June 2013.

Why is the convexity found for market-share changes, not for net flows? New and small equity funds could be a significant driving force of this questionable phenomenon. During our sample period, a remarkable increase occurs in the number of equity funds together with the rapid growth of the equity and pension markets. Before our sample period, a relatively limited number of equity funds existed in the Unit-

\footnotetext{
${ }^{11}$ The disposition effect is found only in the high performance domain not in the low performance domain, which is called the asymmetric disposition effect in this study.

${ }^{12}$ Although the convexity of market-share changes is tested using 1month return as a performance measure but with invariant piecewise break points,we do not report its results given space limitations. We fail to find any convexity in the test.
}

ed States. The number of new or small equity funds is not as high as in our sample period. ${ }^{13}$ Net flows might have very similar behavior to that of market-share changes before 1994 because of this relatively small number of new and small funds. However, since 1994, net flows and market-share changes behave differently given the large number of new and small funds. Investment behavior revealed by fund characteristics can be perceived very differently by the choice of fund flow measure, net flow or market-share change, which are deeply studied in the next section. Needless to say, fund families are concerned with market shares because of their direct relationship to management fees. Net flows need not be directly related to management fees. Hence, they are not necessarily related to such an agency problem.

The estimation results for inflow shares are slightly different from those for inflows in Panel A. When we exclude all control variables in equation (5), the coefficient of High is still the largest among the coefficients of performance variables but that of Low is larger than that of Mid. Inflow shares seem to have no convex relationship with past performance. The result completely reverses when the control variables are included. In equations (6) and (7), inflow shares have an obvious convex relationship with past performance, which is consistent with the case of inflows in Panel A. Hence, we can state that the behavior of inflow shares is also consistent with the prediction model by Lynch and Musto (2003). Meanwhile, out flow shares seem to have a concave, not convex, relationship with past performance when no control variables are included. This concave relationship is supported by the graph of outflow shares in Panel B of Figure 2. However, if control variables are included in equations (6) and (7), a convex relationship is again found between outflow shares and past performance, a finding that is consistent with that observed for outflows in Panel A. This convex relationship indicates that outflow shares slightly increase in the high performance domain. This increase is likely to be evidence of the asymmetric disposition effect, i.e., a tendency to sell winners too early.

The implication of inflow and outflow shares is that they explain why market-share changes have a convex relationship with past performance. Now, we combine the shapes of the inflow and outflow shares in Fig. (2) with the estimation

\footnotetext{
${ }^{13}$ Whereas the number of sample funds is 398 for Chevalier and Ellison (1997) and 690 for Sirri and Tufano (1998), that of this study is 4,418 .
} 
results in Panel B of Table 3. ${ }^{14}$ The differences between inflow and outflow shares remain uniform given their similar behavior in the low performance domain (i.e., bottom $20 \%$ in performance). Outflow shares play a role in forming such uniform differences. This similar behavior of inflow and outflow shares is confirmed by the similar coefficients (0.0957 and 0.0636, respectively) of Low between them in equation (5). Consequently, market-share changes show an almost flat shape in the low performance domain. In the middle performance domain (i.e., middle $60 \%$ in performance), inflow shares show a monotonic increase with performance but outflow shares remain at a stable level. Naturally, market-share changes grow slowly with increases in performance. Finally, in the high performance domain (i.e., top $20 \%$ in performance), inflow shares show a dramatic increase with performance but outflow shares do not change much in line with performance. Hence, market-share changes increase very rapidly with performance, which is the consequence of the behavior of inflow shares. In summary, for the convex relationship between market-share changes and past performance, outflow shares play an important role in the low performance domain and inflow shares play an important role in the middle and high performance domains. Such a convex relationship of market-share changes with past performance indicates the existence of an agency problem between fund investors and managers.

\section{QUANTILE ANALYSIS}

\subsection{Quantile Regressions}

Generally, regression analysis assumes that each probability distribution for $y$ (response variable) has the same standard deviation regardless of the $\mathrm{x}$-value (predictor). This assumption is the "so called" homoscedasticity. Then, in the piecewise linear regressions, fund flows should have homogeneity of variance among the performance groups. If not, the inferences and conclusions might be incorrect. To corroborate the homoscedasticity of fund flows, we draw the boxplots of net flows and market-share changes for the five performance ranking groups in Fig. (3). We focus only on net flows and market-share changes. The first boxplot indicates the worst performance, and the fifth boxplot indicates the best performance. The height of the box or dashed line is important to identify the dispersion of the fund flows in each performance group.

Fig. (3) shows the boxplots of the EDGAR net flows and market-share changes for the five performance ranking groups. The ceiling of the box indicates the value of the $75 \%$ quantile, and the bottom, that of the $25 \%$ quantile. The top of the dashed line indicates the value of $99.5 \%$ quantile, and the bottom, that of the $0.5 \%$ quantile. Net flows for the fifth ranking group show the peerlessly largest dispersion, and those for the first and fourth ranking groups, a relatively large dispersion. The dispersion of market-share changes is also largest in the fifth ranking group, which indicates that net flows and market-share changes have no homoscedasticity among the performance groups.

\footnotetext{
${ }^{14} \mathrm{~A}$ similar reasoning can be applied to the net flow-performance relationship.
}
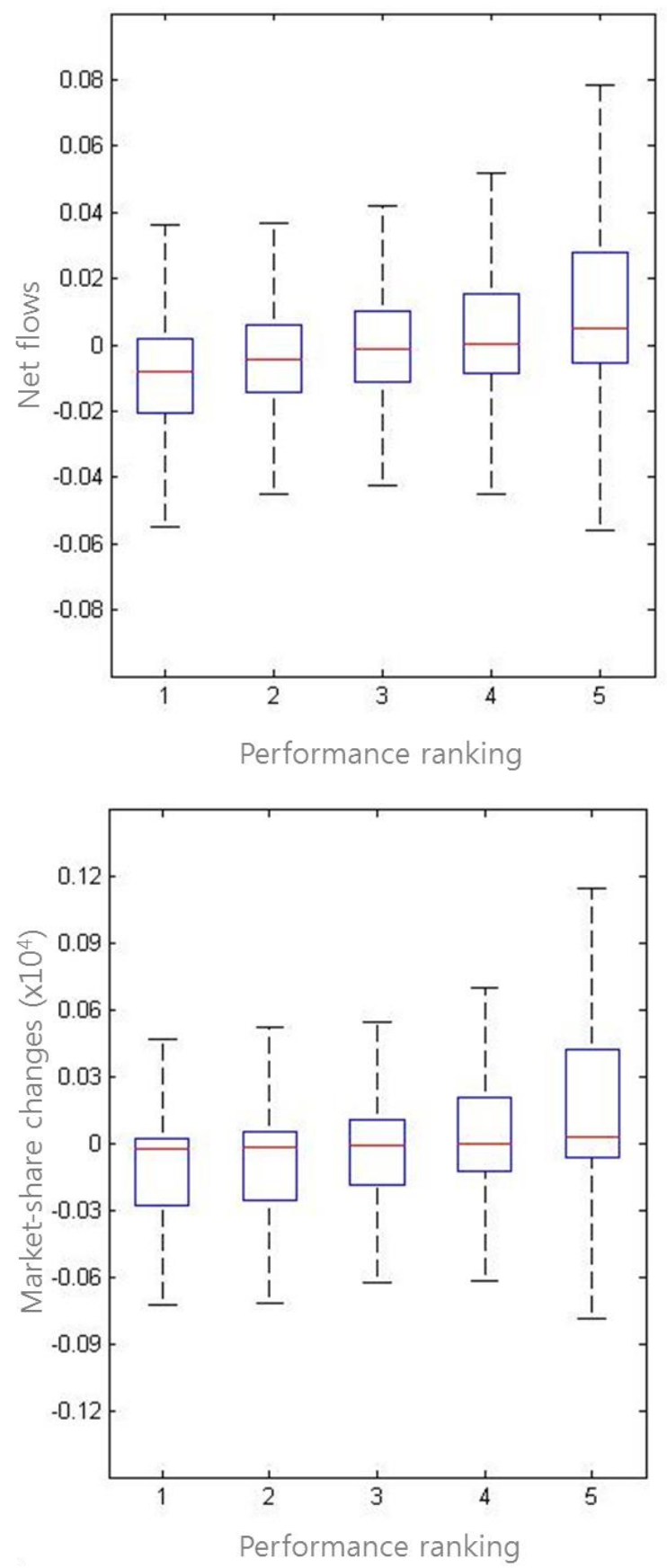

Fig. (3). Boxplots of net flows and market-share changes for the 5 performance groups. This figure shows the boxplots of net flows and market-share changes for the 5 performance groups. The box ceiling indicates the value of the $75 \%$ quantile, and the bottom, that of the $25 \%$ quantile. The top of the dashed line indicates the value of the $99.5 \%$ quantile, and the bottom, that of the $0.5 \%$ quantil.

From the boxplots in Fig. (3), we understand that fund flows may not satisfy the assumption of homoscedasticity. In the absence of homoscedasticity, Koenker and Basset (1978) suggest a quantile regression for a more comprehensive analysis of the relationship between variables. Whereas the ordinary least squares (OLS) method eestimates the conditional mean of the response variable given certain predictor variable values, quantile regression aims at estimating either the conditional median or other quantiles of the response 

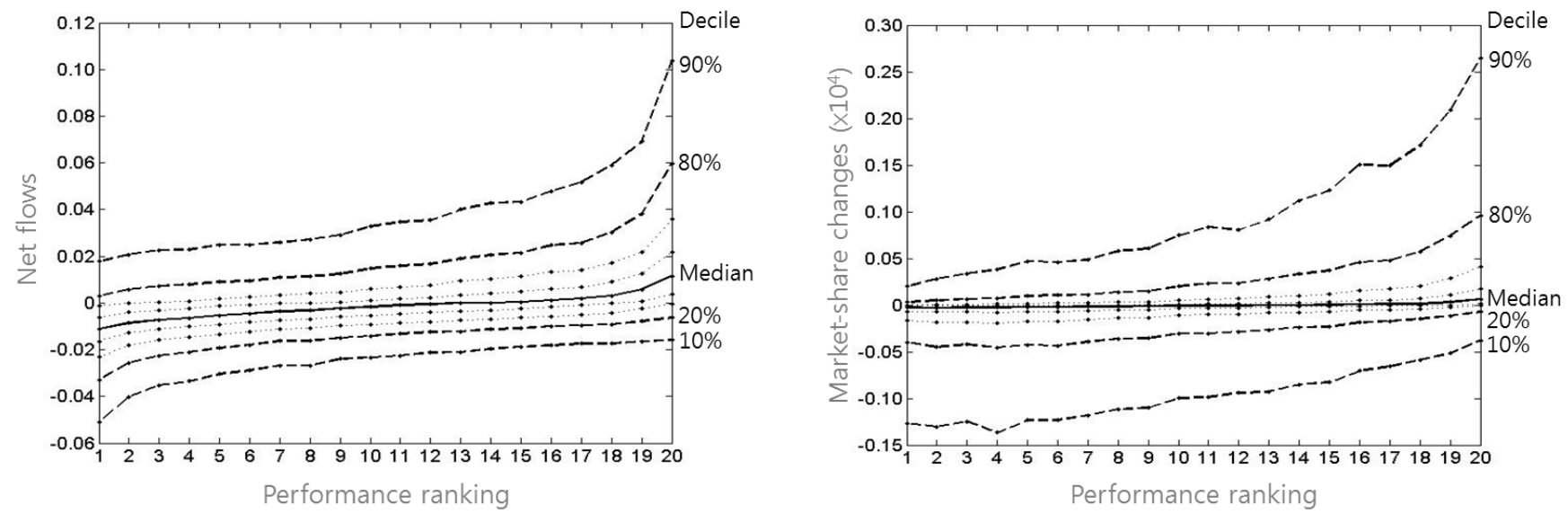

Fig. (4). Quantile lines of net flows and market-share changes for the 20 performance groups. This figure presents quantile lines of net flows and market-share changes for the 20 performance groups from the $10 \%$ quantile to the $90 \%$ quantile.

variable to provide a more complete view of a possible causal relationship among the variables. Following Koenker and Basset (1978), we attempt to apply the following $\tau$ th quantile regression to the flow-performance relationship:

$$
\operatorname{Min}_{\beta \in R^{p}} \sum \rho_{\tau}\left(y_{i}-\xi\left(x_{i}, \beta\right)\right)
$$

where $\mathrm{p}$ is the number of coefficients, $\rho_{\tau}(\cdot)$ is the tilted absolute value function, $y_{i}$ is a response variable, $x_{i}$ is a vector of predictor variables, $\beta$ is a vector of coefficients, and $\xi\left(x_{i}, \beta\right)$ is a regression function. In this study, the response variable is fund flow and the predictor variables consist of Low, Mid, and High. We estimate piecewise linear regressions in equation (5) using the quantile regression method. ${ }^{15}$

Before applying the quantile regression method to fund flows, we preliminarily draw the quantile lines for the 20 performance groups. Fig. (4) shows the quantile lines of the EDGAR net flows and market-share changes. Noteworthy is that the $90 \%$ quantile line of the net flows seems to be convex for the 20 performance groups but the $10 \%$ quantile line seems to be concave. High quantile lines are likely to show convexity, whereas low quantile lines tend to show concavity. The median quantile line of the net flows is flatter than the mean line in Panel A of Fig. (1). These quantile lines reveal that the traditional OLS regression analysis of net flows may lead to incorrect inferences because of heteroscedasticity. In contrast to net flows, market-share changes seem to show convex lines for all quantiles although they also do not have homoscedasticity as shown in Figure 3. The curvature of the line (i.e., convexity) enlarges as the quantile increases. The highest quantile line seems to be clearly convex. However, convexity (or concavity) should be tested for both flow measures to reach a scientific conclusion.

Table 4 shows the results of equation (5) estimated using the quantile regression method. Five quantiles $(10 \%, 20 \%, 50 \%$, $80 \%$, and $90 \%$ ) are selected for estimation and test. As pre-

\footnotetext{
${ }^{15}$ Equations (7) and (8) can be estimated using the quantile regression method. For simplicity, we report the estimation results of equation (5).
}

viously mentioned, the High-Mid indicates the convexity or concavity in the middle and high performance domains and the Mid-Low indicates similarly in the low and middle performance domains. The coefficients for the constant terms are omitted in Table 4. Panel A presents the results for the EDGAR net flows. The $50 \%$ (median)quantile results are not much different from those of the OLS estimation in Table 3. A convex relationship is observed only in the middle and high performance domains, not in the low and middle performance domains. Surprisingly, the $10 \%$ quantile shows a concave relationship, whereas the $90 \%$ quantile shows a strong convex relationship, implying that the agency problem between fund investors and managers might be evident only for the funds with higher net flows, not for the funds with lower net flows. Funds with higher net flows could be relatively small, as suggested by Spiegel and Zhang (2013). Higher net flows for relatively small funds need not be directly connected to the fund family's profitability. Although the fund characteristics in the high and low quantiles require further investigation, just the above convex relationship of the $90 \%$ quantile may not be easily related to an agency problem.

Panel B presents the results for market-share changes. As for net flows, the $50 \%$ quantile results are also not much different (i.e., flatter) from those of the OLS estimation. Notably, a convex relationship is observed in all quantiles, which strikingly contradicts the case of net flows. The lower part of Panel B indicates that the curvature of the convexity is not the same among the quantiles. We understand that the convexity of market-share changes is more pronounced from the lower quantile to the higher quantile. In any event, quantile regressions show that market-share changes are more related to the convex flow-performance relationship than net flows. Hence, we conclude that market-share changes are a more appropriate measure of fund flows than net flows from the viewpoint of the agency problem between fund investors and managers.

\subsection{Characteristic Analysis of Quantile Groups}

The quantile regressions show that net flows have a convex relationship with past performance only for the higher quantiles, but market-share changes have such a relationship for 
Table 4. Quantile Regressions of EDGAR Net Flows and Market-share Changes.

This table shows the estimation results of equation (5) using the quantile regression method. Five quantiles $(10 \%, 20 \%, 50 \%, 80 \%$, and $90 \%)$ are selected for estimation. Coefficients for constant terms are omitted. Panel A presents the results for EDGAR net flows. Panel B presents the results for market-share changes.

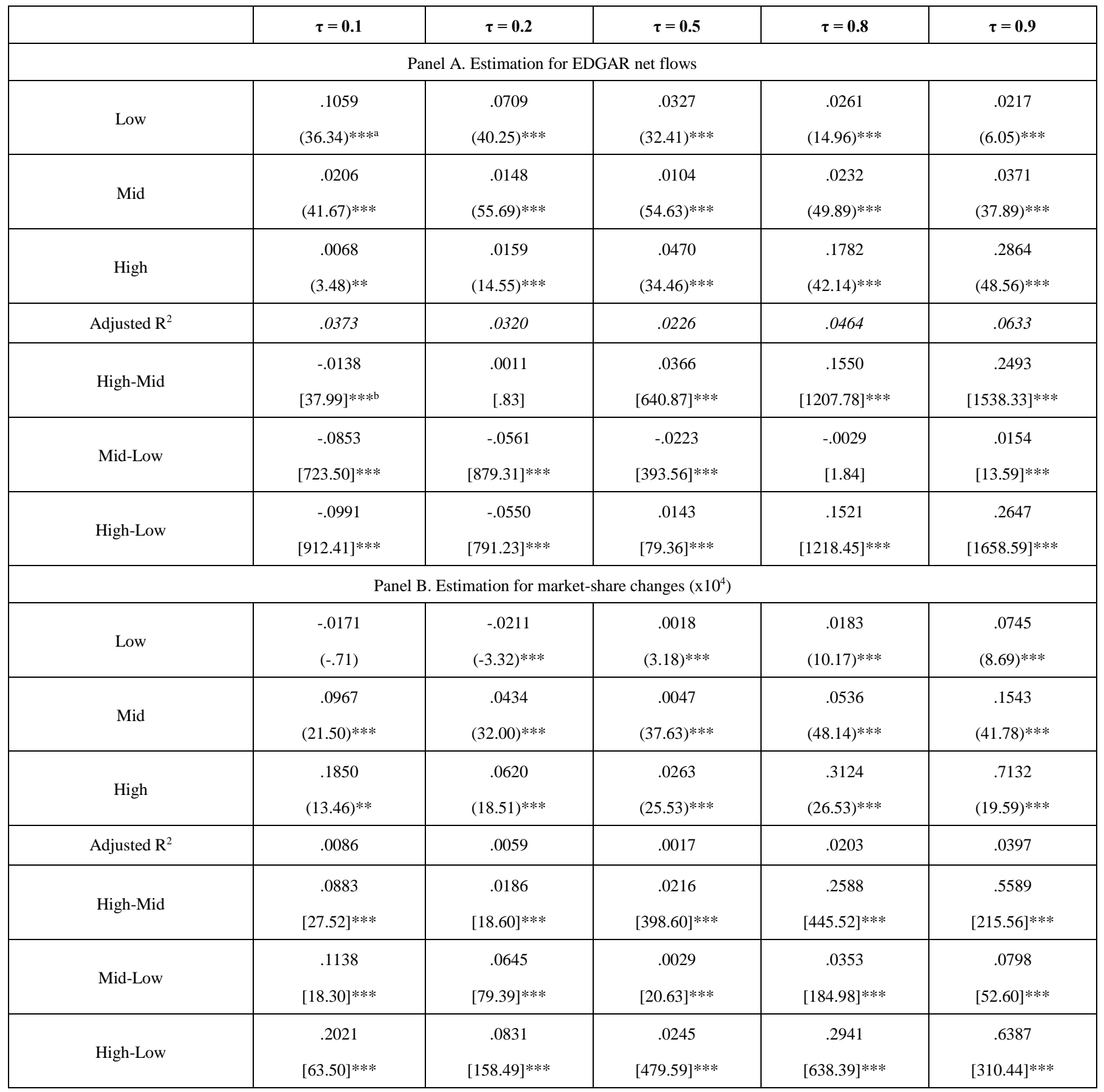

a. t-statistics in parentheses are calculated using White heteroscedasticity-consistent standard errors. *,**, and *** indicate statistical significance at the $10 \%$, $5 \%$ and $1 \%$ levels, respectively.

b. $\chi^{2}$ statistics are in brackets. *, **, and *** indicate statistical significance at the $10 \%, 5 \%$ and $1 \%$ levels, respectively. 
Table 5. Characteristics of Quantile Groups for Net Flows and Market-share Changes.

This table shows the characteristics of the lower- and higher-quantile funds. We define the lower- and higher-quantile funds as funds below the $10 \%$-quantile regression line and funds above the $90 \%$-quantile regression line, respectively. Panel A presents the results for net flows, and Panel B presents the results for market-share changes.

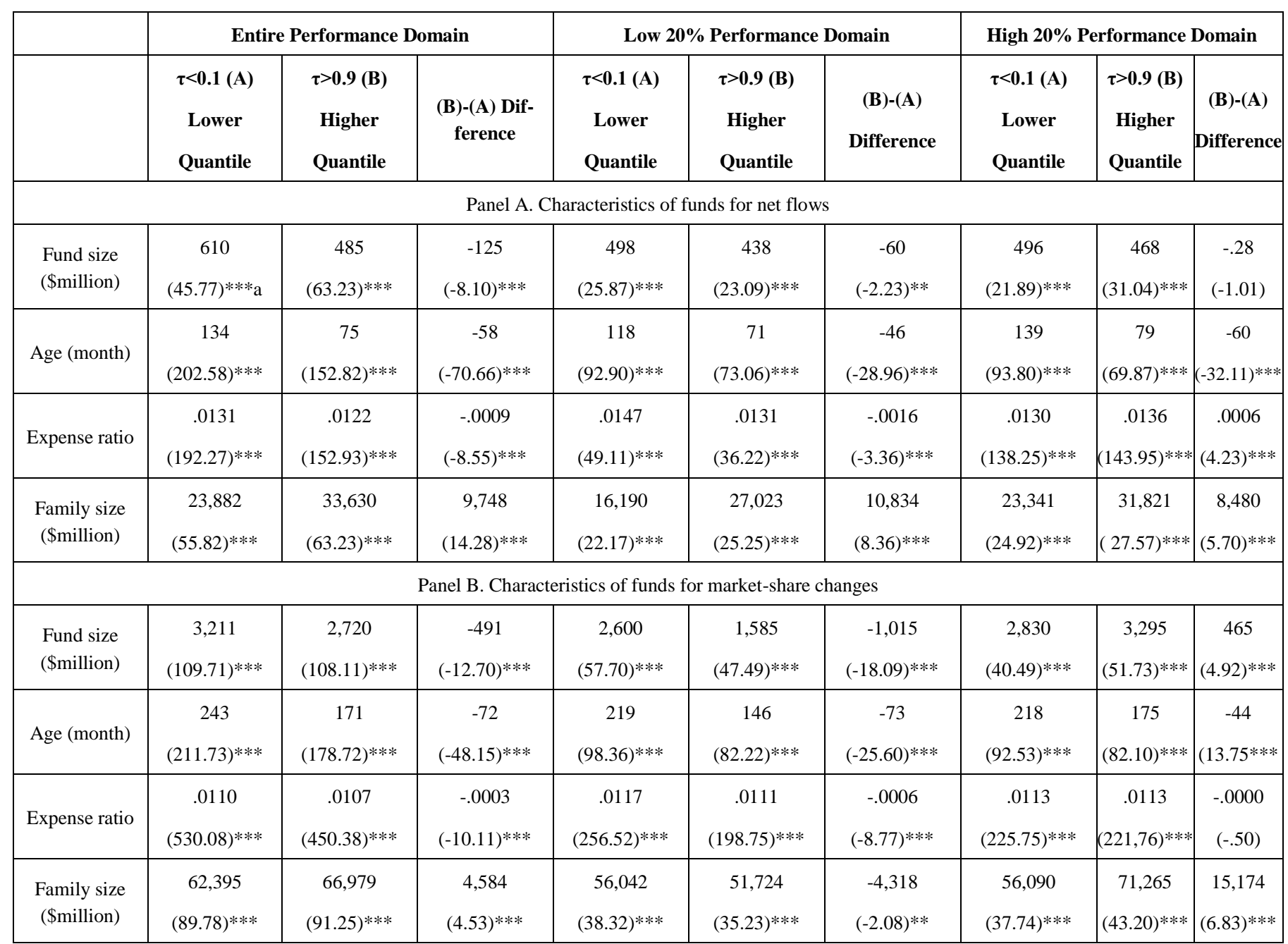

a. t-statistics are in parentheses. $* * *$, and $* * *$ indicate statistical significance at the $10 \%, 5 \%$ and $1 \%$ levels, respectively.

all quantiles. Then, the next question is "Do any of the fund characteristics differ between the low and high quantiles?" We focus on the characteristics of fund size, age, expense ratio, and family size because they may be directly related to the profitability of fund families. We define lower- and higher-quantile funds as funds below the $10 \%$-quantile regression line and funds above the $90 \%$-quantile regression line, respectively. ${ }^{16}$ Middle-quantile funds are defined as funds between the $10 \%$ and $90 \%$ quantile regression lines. As suggested by Spiegel and Zhang (2013), net flows are more sensitive to past performance for small funds than for large funds, which implies that the lower- and higher-quantile funds for net flows must be relatively smaller than the middle-quantile funds. In contrast to net flows, by definition in (3), market-share changes are more sensitive to past perfor-

16 Even if we use $20 \%$ - and $80 \%$-quantile regression lines for classifying lower- and higher-quantile funds, respectively, the results do not change qualitatively. mance for large funds than for small funds. Naturally, the lower- and higher-quantile funds for market-share changes must be relatively larger than the middle-quantile funds.

Panel A of Table 5 presents the characteristics of the lowerand higher-quantile funds for net flows. In the entire performance domain, the higher-quantile funds are smaller in fund size, younger, less expensive, and smaller in family size than the lower-quantile funds. Because net flows are more sensitive to past performance for small funds than large funds, both lower- and higher-quantile funds must be small. Although not reported in Table 5 , the average size of middlequantile funds is $\$ 1,548$ million in the entire performance domain, which is much larger than that for the higher- and lower-quantile funds. Hence, fund size between the lowerand higher-quantile funds should be compared in a relative sense. As suggested by Spiegel and Zhang (2013), the higher-quantile funds (i.e., hot money funds) are much smaller 
and younger than the lower-quantile funds. ${ }^{17}$ The low and high $20 \%$ performance domains also show the same characteristics, indicating that a convex relationship can be driven by hot money funds because the higher-quantile funds lead to convexity.

The expense ratio is lower for the higher-quantile funds than for the lower-quantile funds in the entire performance domain. However, in the high (low) 20\% performance domain, the higher-quantile funds have a slightly higher (lower) expense ratio than the lower-quantile funds. This finding is weakly consistent with the hypothesis that fund families earn more money by enhancing the performance of funds with a higher expense ratio. Meanwhile, fund families may artificially enhance the performance of a specific fund to induce net flows or to increase market share. Large fund families are able to easily conduct such a strategy (i.e., wealth transfer, tournament behavior, and portfolio pumping). If so, the higher-quantile funds have a larger family size than the lower-quantile funds. As expected, higher-quantile funds have a larger family size $(\$ 33,630 \mathrm{M})$ than lower-quantile funds $(\$ 23,882 \mathrm{M})$ in the entire performance domain. The same is true in the low and high performance domains.

The empirical evidence in section 4 shows that market-share changes have a convex relationship with past performance. If market-share change is a better measure for fund flows than net flow from the viewpoint of the agency problem, we expect the following characteristics of the higher- and lowerquantile funds: in the high performance domain, the higherquantile funds must be larger than the lower-quantile funds because the largest increase in market share is more possible for large funds than for small funds and it must benefit a fund family; in the low performance domain, the higherquantile funds must be smaller than the low-quantile funds because the decreases in the market shares of small funds must be smaller than those of large funds. Moreover, in the presence of low performance, protecting small funds' market shares from drastically plummeting is easier than protecting large funds. Panel B presents the characteristics of the lowerand higher-quantile funds for market-share changes. As expected, the higher-quantile funds in the high performance domain are larger than the lower-quantile funds and vice versa in the low performance domain. ${ }^{18}$ This finding has an important implication for understanding the convex flowperformance relationship. As shown in Figure 4, the convex flow-performance relationship is largely attributable to higher-quantile funds. These funds are relatively large in the high performance domain and relatively small in the low performance domain. Hence, we conclude that relatively large funds in the high performance domain and relatively small

\footnotetext{
${ }^{17}$ In fact, the average size of funds above the higher-quantile regression line is smaller than that of any other quantile group funds.

18 As previously mentioned, the lower- and higher-quantile funds for market-share changes must be relatively larger than the middlequantile funds because market-share changes are more sensitive to past performance for large funds than for small funds. Although not reported in Table 5, the average size for the middle-quantile funds is only $\$ 363$ million in the entire performance domain, which is much smaller than those of the lower- and higher-quantile funds.
}

funds in the low performance domain play an important role in the convex relationship.

The higher-quantile funds are younger in the low and high performance domains. No difference in expense ratio exists between the lower- and higher-quantile funds in the high performance domain, revealing that fund size is more essential than expense ratio for earning higher management fees by enhancing fund performance. Family size has another important implication because it might be related to family strategies to artificially enhance fund performance. A family strategy must be easier for a large family than for a small family. As expected, in the high performance domain, the higher-quantile (lower-quantile) funds belong to relatively large (small) families and vice versa in the low performance domain. This finding proves the possibility of using family strategy to artificially enhance fund performance.

\section{CONCLUDING REMARKS}

This study compares market-share changes with net flows to revisit the fund flow-performance relationship. Market-share changes (net flows) are decomposed into inflow and outflow shares and other parts (inflow and outflow) to explain their behavior. We employ quantile regression to obtain a more comprehensive flow-performance relationship.

During the period from January 1994 through June 2013, market-share changes have a convex relationship with past performance but net flows do not. The non-convex net flowperformance relationship is simply a consequence created by the combination of the convex inflow- and outflowperformance relationships. For the convex relationship of market-share changes, outflow shares play an important role in the low performance domain and inflow shares play an important role in the middle and high performance domains. Quantile regressions show that net flows have a convex (concave) relationship for the $90 \%(10 \%)$ quantile, however, market-share changes have a convex relationship for all quantiles.

Fund characteristics such as fund size, fees, and age, are directly related to the profitability of fund families. Characteristic analysis of quantile groups shows that relatively large funds in the high performance domain and relatively small funds in the low performance domain play an important role in the convex relationship of market-share changes with past performance. Also, in the high performance domain, the higher-quantile funds have a slightly higher expense ratio and younger age.

Market share change is determined by both strategies of fund families and investment decisions and preferences of fund investors. Market share is an important variable to study because the revenues of mutual funds families are directly related to a function of total assets under management. An increase in market share changes can allow a fund family to increase economies of scale benefits, widen customer base, and enhance their reputation in the fund industry. The fact that market-share changes have a convex relationship with past performance can show evidence of an existence of an agency problem between fund investors and fund families. This study suggest that market-share change suggested by 
Spiegel and Zhang (2013) is a better measure for fund flows than net flows from the viewpoint of the agency problem.

\section{CONFLICT OF INTEREST STATEMENT}

The authors declare that they have no conflict of interest.

\section{ACKNOWLADGEMENT}

This paper was based on the first author's Ph.D. dissertation, and further developed when she was visiting University of Cincinnati. The authors thank Yong Kim (UC), Kiyool Ohk, Jinwoo Kim, Youngdeok Kim, Byungho Choi for helpful comments.

\section{REFERENCES}

Barber, B., T. Odean, and L. Zheng, 2005, Out-of-sight, Out-of-mind: The Effects of Expenses on Mutual Fund Flows, Journal of Business 78, pp. 261-292.

Bergstresser, D. and J. Poterba, 2002, Do After-tax Returns Affect Fund Inflows?, Journal of Financial Economics 63, pp. 381-414.

Brown, K. C., W. V. Harlow, and L. T. Starks, 1996, Of Tournaments and Temptations: An Analysis of Managerial Incentives in the Mutual Fund Industry, Journal of Finance 51, pp. 85-110.

Carhart, M., R. Kaniel, D. Musto, and A. Reed, 2001, Leaning for the Tape: Evidence of Gaming Behavior in Equity Mutual Funds, Journal of Finance 57, pp. 661-693.

Chevalier, J. and G. Ellison, 1997, Risk Taking by Mutual Funds as a Response to Incentives, Journal of Political Economy 105, pp. 11671200.

Edelen, R., R. Evans, and G. Kadlec, 2012, Disclosure and Agency Conflict: Evidence from Mutual Fund Commission Bundling, Journal of Financial Economics 103, pp. 308-326.

Gaspar, J. M., M. Massa, and P. Matos, 2006, Favoritism in Mutual Fund Families? Evidence on Strategic Cross-Fund Subsidization, Journal of Finance 61, pp. 73-104.

Hu, G., R. McLean, J. Pontiff, and Q. Wang, 2014, The Year-End Trading Activities of Institutional Investors: Evidence from Daily Trades, Review of Financial Studies 27, pp. 1593-1614.
Huang, J., K. D. Wei, and H. Yan, 2007, Participation Costs and the Sensitivity of Fund Flows to Past Performance, Journal of Finance 62, pp. 1273-1311.

Huang, J., C. Sialm, and H. Zhang, 2011, Risk Shifting and Mutual Fund Performance, Review of Financial Studies 24, pp. 2575-2616.

Ippolito, R. A., 1992, Consumer Reaction to Measures of Poor Quality: Evidence from the Mutual Fund Industry, Journal of Law and Economics 35, pp. 45-70.

Jain, P. C. and J. S. Wu, 2000, Truth in Mutual Fund Advertising: Evidence on Future Performance and Fund Flows, Journal of Finance 55, pp. 937-958.

Kempf, A. and S. Ruenzi, 2008, Tournaments in Mutual Fund Families, Review of Financial Studies 21, pp. 1013-1036.

Koenker, R. and G. Bassett, 1978, Regression Quantiles, Econometrica 46, pp. 33-50

Lee, B., M. Paek, Y. Ha, and K. Ko, 2015, The Dynamics of Market Volatility, Market Return, and Equity Fund Flow: International Evidence, International Review of Economics and Finance 35, pp. 214-227.

Lynch, A. W. and D. K. Musto, 2003, How Investors Interpret Past Fund Returns, Journal of Finance 58, pp. 2033-2058.

Nanda, V., Z. Wang, and L. Zheng, 2004, Family Values and the Star Phenomenon, Review of Financial Studies 17, pp. 667-698.

Rakowski, D., 2010, Fund Flow Volatility and Performance, Journal of Financial and Quantitative Analysis 45, pp. 223-237.

Rakowski, D. and X. Wang, 2009, The Dynamics of Short-Term Mutual Fund Flows and Returns: A Time-Series and Cross-Sectional Investigation, Journal of Banking and Finance 33, pp. 2102-2109.

Shefrin, H. and M. Statman, 1985, The Disposition to Sell Winners Too Early and Rise Losers Too Long, Journal of Finance 40, pp. 777 790.

Sialm, C., L. Starks, and H. Zhang (2015), Defined Contribution Pension Plans: Sticky or Discerning Money?, Journal of Finance 70, pp. 805-838.

Sirri, E. R. and P. Tufano, 1998, Costly Search and Mutual Fund Flows, Journal of Finance 53, pp. 1589-1621.

Spiegel, M. and H. Zhang, 2013, Mutual Fund Risk and Market Share Adjusted Fund Flows, Journal of Financial Economics 108, pp. 506528. 